\title{
Pengaruh Model Cooperative Integrated Reading and Composition Terhadap Hasil Belajar Siswa Pada Materi Ekosistem di SMA Nurul Amaliyah Tanjung Morawa
}

\author{
Pandu Prabowo $^{(1)}$,Melissa Chaniago ${ }^{(2)}$ \\ ${ }^{(1)}$ Guru Honor SMA Nurul Amaliyah Medan Tanjung Morawa \\ ${ }^{(2)}$ Dosen PNS DPK Kopertis Fakultas Kedokteran Universitas Islam Sumatera Utara \\ panduprabowo@ fkip.uisu.ac.id ${ }^{(1)}$,melissachngo@yahoo.co.id ${ }^{(2)}$
}

\begin{abstract}
ABSTRAK
Penelitian ini bertujuan untuk mengetahui apakah terdapat pengaruh penggunaan Model Cooperative Integrated Reading and Composition terhadap hasil belajar siswa pada materi Ekosistem di SMA Nurul Amaliyah Tanjung Morawa. Penelitian ini dilaksanakan pada tanggal 23 Maret sampai 21 Mei 2014. Penelitian ini menggunakan metode eksperimen semu (Quasi experiment) dengan populasi penelitian adalah seluruh siswa di kelas X SMA Swasta Nurul Amaliyah Tanjung Morawa Tahun Pembelajaran 2013/2014 yang berjumlah 40 orang yang kemudian seluruh populasi dijadikan sampel keseluruhan (total sampling). Instrumen dalam penelitian ini adalah tes hasil belajar berupa pre- test dan post- test. Hasil belajar siswa yang menggunakan model Cooperative Integrated Reading and Composition diperoleh nilai siswa yang tuntas sesuai Kriteria Ketuntasan Minimal (KKM) 70 adalah sebanyak 32 orang $(80 \%)$ dan yang tidak tuntas sebanyak 8 orang (20\%) dengan nilai rata- rata 77,95 dan standart deviasi 9,55. Hasil uji normalitas diperoleh Lo $<\mathrm{L}_{\text {tabel }}$ yaitu $0,1131<0,1401$ dinyatakan bahwa data berdistribusi normal sedangkan hasil uji homogenitas diperoleh $\mathrm{F}_{\text {hitung }}<\mathrm{F}_{\text {tabel }}=1,1<1,71$ dinyatakan data mempunyai varians yang sama atau homogen. Hasil uji hipotesis menggunakan uji t diketahui rata- rata dari perbedaan pre test dengan post test adalah sebesar 15,45 dan jumlah kuadrat deviasi sebesar 2127,9 dengan nilai ini maka diperoleh $t_{\text {hitung }}>t_{\text {tabel }}$ atau 13,21 > 1,68 maka Ha diterima dan Ho ditolak, sehingga dinyatakan bahwa ada pengaruh yang signifikan penggunaan model Cooperative Integrated Reading and Composition terhadap hasil belajar siswa pada materi ekosistem
\end{abstract}

Kata kunci : Cooperative Intgrated Reading Composition, Hasil Belajar Siswa

\section{PENDAHULUAN}

Pendidikan adalah suatu proses pengembangan diri individu mengenai kepribadian seseorang yang dilakukan secara sadar dan penuh tanggung jawab untuk dapat meningkatkan pengetahuan, keterampilan dan sikap serta nilai- nilai moral sehingga mampu menyesuaikan diri dengan lingkungan dan dengan pengetahuan yang dimilikinya. Di dalam kegiatan pembelajaran harus memperhatikan beberapa faktor diantaranya yaitu faktor siswa, guru dan materi pelajaran. Apabila faktor- faktor yang mempengaruhi tujuan pembelajaran tersebut mengalami masalah dalam pelaksanaannya, maka tujuan pendidikan yang diharapkan tidak akan tercapai dan mutu pendidikan akan rendah. Penyebab rendahnya mutu pendidikan di Indonesia adalah masalah efektifitas, efisiensi dan standart pengajaran di sekolah- sekolah. Selain itu ada beberapa permasalahan khusus dalam dunia pendidikan yaitu rendahnya sarana fisik, rendahnya kualitas guru, rendahnya kesejahteraan guru, kurangnya prestasi siswa dan rendahnya kesempatan pemerataan pendidikan, rendahnya relevansi pendidikan dengan kebutuhan serta mahalnya biaya pendidikan. Untuk meningkatkan mutu pendidikan maka diperlukan strategi pembelajaran dan program mengajar yang tepat misalnya dalam hal kegiatan seorang guru yang menyampaikan isi materi pelajaran kepada siswanya agar memperoleh kualitas pendidikan yang baik. Guru yang menyampaikan isi materi dalam pembelajaran Biologi misalnya, jika dalam 
Siska Anggreni Lubis, Mega Dwi Pertiwi, Saiful B : Pengaruh Model Cooperative Integrated Reading and Composition Terhadap Hasil Belajar Siswa Pada Materi Ekosistem di SMA Nurul Amaliyah Tanjung Morawa

penyampaiannya kepada siswa dengan menggunakan model yang tidak variatif akan menjadikan siswa merasa jenuh dan bosan di kelas, akhirnya materi yang disampaikan guru tidak sepenuhnya dimengerti oleh siswa. Kurangnya minat siswa ini mengakibatkan dampak buruk yaitu tidak tercapainya tujuan pembelajaran yang diinginkan sehingga menyebabkan hasil belajar rendah. Biologi merupakan cabang dari ilmu pengetahuan yang mempelajari tentang makhluk hidup, bagaimana interaksinya satu sama lain dan bagaimana interaksinya dengan lingkungan. Dalam Biologi maupun pelajaran yang lain pada akhirnya guru akan menilai hasil belajar yang diperoleh setiap siswa setelah proses kegiatan belajar mengajar selesai dilaksanakan. Hasil belajar ialah tingkat penguasaan terhadap materi yang telah dicapai siswa dalam proses belajar mengajar. Hasil belajar siswa itu sendiri dapat diketahui dengan cara diukur dengan menggunakan tes, dimana dari hasil tes ini guru akan memberikan skor terhadap kemampuan yang diperoleh siswa dalam menjawab soal yang diberikan. Siswa yang mampu menjawab tes dengan benar maka akan memperoleh skor yang tinggi dan meningkatkan hasil belajar, sedangkan siswa yang tidak mampu menjawab tes akan memperoleh skor yang rendah dan hasil belajarnya juga akan menurun. Berdasarkan hasil wawancara yang telah peneliti lakukan dengan guru Biologi SMA Nurul Amaliyah, masalah yang sering dihadapi guru dalam kelas adalah siswa kurang aktif dalam kegiatan pembelajaran dan siswa juga kurang tertarik dalam pelajaran Biologi sehingga pada hasil belajar ulangan harian siswa diperoleh $60 \%$ dari jumlah siswa di bawah nilai KKM (kriteria ketuntasan minimal) yaitu 70. Dalam pelajaran Biologi ini salah satu upaya untuk meningkatkan hasil belajar dapat digunakan model pembelajaran kooperatif. Model kooperatif atau cooperative learning ini mengarah pada kegiatan belajar kelompok dan bekerja sama untuk memahami suatu materi yang dipimpin oleh guru, dimana guru menyediakan bahan- bahan atau materi dan pertanyaan atau kasus yang harus dibahas siswa dalam setiap kelompoknya. Siswa akan lebih aktif dalam kegiatan belajar dengan model kooperatif ini. Siswa dapat belajar secara optimal dan akan lebih mudah dalam hal memahami materi misalnya pada materi pokok ekosistem. Dalam materi ekosistem khususnya pencemaran lingkungan membahas tentang faktor perubahan lingkungan, pencemaran, parameter pencemaran lingkungan, dampak pencemaran dan usaha dalam mencegah pencemaran lingkungan. Penerapan Model pembelajaran Cooperative Integrated Reading and Composition dimaksudkan untuk meningkatkan kemampuan siswa menyimpulkan suatu materi dalam membangun konsep tingkat pemahaman siswa. Model ini sangat baik digunakan agar siswa dapat lebih mendalami secara rinci dan detail tentang materi yang diajarkan kepadanya (Istarani, 2012:113). Model pembelajaran Cooperative Integrated Reading and Composition ini digunakan dalam kegiatan pembelajaran di kelas untuk melihat apakah model ini dapat memberikan pengaruh terhadap hasil belajar siswa. Berdasarkan hasil pemikiran di atas maka penulis tertarik untuk melakukan penelitian dengan judul "Pengaruh Model Cooperative Integrated Reading and Composition Terhadap Hasil Belajar Siswa Pada Materi Ekosistem Di SMA Nurul Amaliyah Tanjung Morawa",

\section{METODE PENELITIAN}

\section{A. Prosedur Penelitian}

Prosedur yang dilaksanakan dalam penelitian ini adalah sebagai berikut:

\section{a. Tahap persiapan}

1. Pengurusan surat izin penelitian dari Fakultas Keguruan dan Ilmu Pendidikan Universitas Islam Sumatera Utara 
Siska Anggreni Lubis, Mega Dwi Pertiwi, Saiful B : Pengaruh Model Cooperative Integrated Reading and Composition Terhadap Hasil Belajar Siswa Pada Materi Ekosistem di SMA Nurul Amaliyah Tanjung Morawa

2. Konsultasi dengan kepala sekolah SMA Swasta Nurul Amaliyah Tanjung Morawa untuk memohon izin melakukan penelitian

3. Menyusun Rencana Pelaksanaan Pembelajaran (RPP) tentang keterkaitan kegiatan manusia dengan kerusakan/ pencemaran lingkungan

4. Membuat kisi- kisi soal dari materi yang diajukan dan disusun dalam bentuk pilihan berganda dengan 5 pilihan ( $a, b, c, d$ dan e)

5. Melakukan uji coba instrumen untuk menguji validitas tes

b. Tahap pelaksanaan

1. Melaksanakan pre test untuk mengetahui kemampuan awal siswa

2. Menyampaikan materi kepada siswa dan melakukan proses pembelajaran dengan menggunakan Model pembelajaran Cooperative Integrated Reading and Composition

3. Melaksanakan post test untuk mengetahui hasil belajar siswa setelah menerapkan model pembelajaran CIRC

c. Tahap penyelesaian penelitian

1. Hasil penelitian dan Analisis data

2. Menarik kesimpulan dari hasil penelitian

3. Membuat laporan hasil penelitian

\section{B. Instrumen Penelitian}

Instrumen dalam penelitian ini adalah tes hasil belajar. Tes yang diberikan adalah pre- test dan post- test.

1. Pre- test diberikan sebelum proses belajar mengajar berlangsung. Tes ini dilakukan untuk mengetahui kemampuan dasar siswa tentang materi yang akan diajarkan. Tes diberikan sebanyak jumlah soal yang valid dalam bentuk pilihan berganda dan masing- masing soal mempunyai 5 pilihan yaitu a, b, c, d dan e.

2. Post- test ini diberikan sebagai data hasil belajar siswa yang diberikan setelah proses pembelajaran berlangsung. Tes ini untuk mengetahui sejauh mana hasil belajar siswa yang di ajarkan dengan model Cooperative Integrated Reading and Composition pada materi ekosistem. Tes diberikan sebanyak jumlah soal yang valid dalam bentuk pilihan berganda masing- masing soal mempunyai 5 pilihan yaitu a, b, c, d dan e.

\section{Teknik Analisis Data}

Teknik analisis data dapat dilakukan dengan langkah-langkah sebagai berikut :

1) Menentukan daftar distribusi frekuensi

a. Menentukan data tertinggi dan data terendah

b. Menentukan Range (R) dari setiap kelas

c. Menentukan jumlah atau banyak kelas $B K=1+(3,3) \log n$

d. Menentukan panjang kelas interval : $\mathrm{P}=\mathrm{R} / \mathrm{BK}$

2) Menghitung nilai rata-rata (Mean), median (Me), modus (Mo), dan standar deviasi dari tiap kelas.

a. Menurut Sudjana (2002:67), nilai rata-rata (Mean) dapat dihitung dengan menggunakan rumus sebagai berikut:

$\overline{\mathrm{x}}=\frac{\sum f i x i}{\sum f i}$

Keterangan :

$\bar{x}=$ nilai/skor rata-rata kelas (Mean).

$\mathrm{f}_{\mathrm{i}}=$ frekuensi siswa yang mendapatkan nilai/skor sama

$\mathrm{x}_{\mathrm{i}}=$ nilai tes yang diperoleh pada salah satu kelas yang ada 
Siska Anggreni Lubis, Mega Dwi Pertiwi, Saiful B : Pengaruh Model Cooperative Integrated Reading and Composition Terhadap Hasil Belajar Siswa Pada Materi Ekosistem di SMA Nurul Amaliyah Tanjung Morawa

b. Menurut Sudjana (2002:79), median (Me) dapat dihitung dengan menggunakan rumus sebagai berikut:

$\mathrm{Me}=\mathrm{b}+\mathrm{p}\left(\frac{\frac{1}{2} n-F}{f}\right)$

Keterangan :

$\mathrm{b}=$ batas bawah kelas median

$\mathrm{p}=$ panjang kelas median

$\mathrm{n}=$ ukuran sampel atau banyak data

$\mathrm{F}=$ jumlah semua frekuensi dengan tanda kelas lebih kecil dari tanda kelas median

$\mathrm{f}=$ frekuensi kelas median

c. Menurut Sudjana (2002:77), modus (Mo) dapat dihitung dengan menggunakan rumus sebagai berikut:

$\mathrm{Mo}=\mathrm{b}+\mathrm{p}\left(\frac{b_{1}}{b_{1}+b_{2}}\right)$

Keterangan :

$\mathrm{b}=$ batas bawah kelas modus

$\mathrm{p}=$ panjang kelas modus

$\mathrm{b}_{1}=$ frekuensi kelas modus dikurangi frekuensi kelas interval dengan tanda kelas yang lebih kecil sebelum tanda kelas modus

$\mathrm{b}_{2}=$ frekuensi kelas modus dikurangi frekuensi kelas interval dengan tanda kelas lebih besar sesudah tanda kelas modus.

d. Menurut Sudjana (2002:95), standar deviasi atau disebut simpangan baku dapat dihitung dengan menggunakan rumus sebagai berikut:

$S^{2}=\frac{n \sum f i x i^{2}-\left(\sum f i x i\right)^{2}}{n(n-1)}$

Keterangan :

$\mathrm{S}$ = simpangan baku

$\mathrm{n}=$ jumlah seluruh siswa

$\mathrm{f}_{\mathrm{i}}=$ frekuensi yang sesuai dengan kelas $\mathrm{x}_{\mathrm{i}}$

$\mathrm{x}_{\mathrm{i}}=$ nilai tengah kelas interval

\section{HASIL PENELITIAN}

Untuk mengetahui rata- rata, standart deviasi, median dan modus pada pre test dan post test dapat dilihat pada tabel distribusi frekuensi nilai berikut :

Tabel . Daftar Distribusi Frekuensi Nilai Pre test

\begin{tabular}{|l|l|l|l|l|l|l|}
\hline $\begin{array}{l}\text { Kelas } \\
\text { interval }\end{array}$ & $\begin{array}{l}\text { Frekuensi } \\
\text { (fi) }\end{array}$ & xi & xi $^{2}$ & fi.xi & fi.(xi) & f \% \\
\hline $40-46$ & 2 & 43 & 1849 & 86 & 3698 & 5 \\
\hline $47-53$ & 7 & 50 & 2500 & 350 & 17500 & 17,5 \\
\hline $54-60$ & 10 & 57 & 3249 & 570 & 32490 & 25 \\
\hline $61-67$ & 12 & 64 & 4096 & 768 & 49152 & 30 \\
\hline $68-74$ & 6 & 71 & 5041 & 426 & 30246 & 15 \\
\hline $75-81$ & 3 & 78 & 6084 & 234 & 18252 & 7,5 \\
\hline$\Sigma$ & 40 & 363 & 22819 & 2434 & 151338 & 100 \\
\hline
\end{tabular}


Siska Anggreni Lubis, Mega Dwi Pertiwi, Saiful B : Pengaruh Model Cooperative Integrated Reading and Composition Terhadap Hasil Belajar Siswa Pada Materi Ekosistem di SMA Nurul Amaliyah Tanjung Morawa

Berdasarkan tabel di atas untuk mencari nilai rata- rata pre test yaitu dengan membagi jumlah keseluruhan nilai siswa (fi.xi) 2434 dengan frekuensi jumlah siswa (fi) sebanyak 40 sehingga diperoleh nilai rata-rata pre test $(\overline{\mathrm{x}})$ 60,85 dan standart deviasi 9,1. Median (Me) diperoleh dengan mencari nilai tengah frekuensi kelas median pada fi yaitu 12 sehingga diperoleh nilai median 61,08 dan Modus (Mo) diperoleh dengan mencari frekuensi nilai yang paling sering muncul yaitu 12 sehingga nilai modus yaitu 62,25.

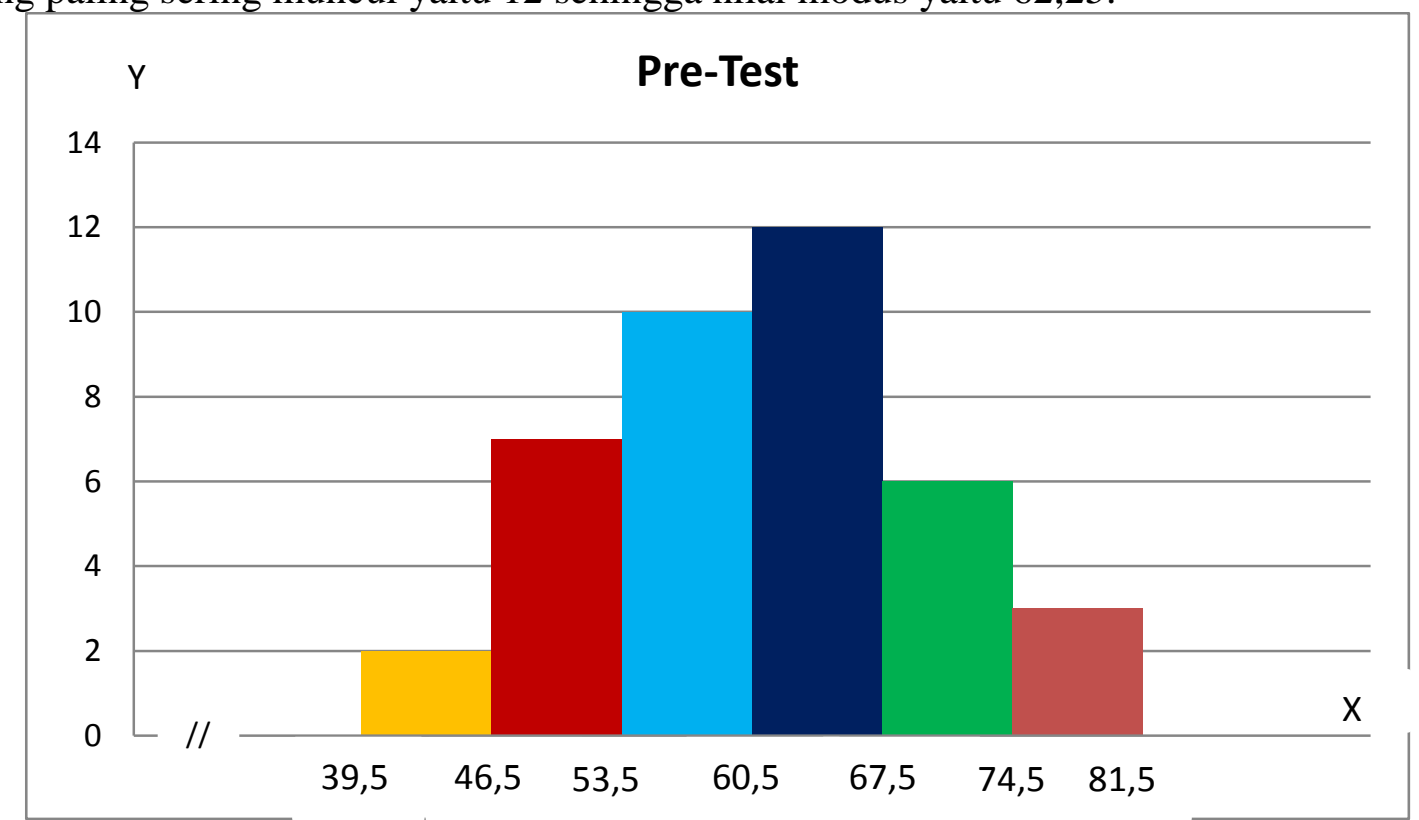

\section{Gambar . Diagram Nilai Pre test Siswa}

Tabel. Daftar Distribusi Frekuensi Nilai Post test

\begin{tabular}{|l|l|l|l|l|l|l|}
\hline $\begin{array}{l}\text { Interval } \\
\text { Kelas }\end{array}$ & $\begin{array}{l}\text { Frekuensi } \\
\text { (fi) }\end{array}$ & $\mathrm{xi}$ & $\mathrm{xi}^{2}$ & fi.xi & fi.(xi) & f \% \\
\hline $57-62$ & 3 & 59,5 & 3540,25 & 178,5 & 10620,75 & 7,5 \\
\hline $63-68$ & 5 & 65,5 & 4290,25 & 327,5 & 21451,25 & 12,5 \\
\hline $69-74$ & 6 & 71,5 & 5112,25 & 429 & 30673,5 & 15 \\
\hline $75-80$ & 7 & 77,5 & 6006,25 & 542,5 & 42043,75 & 17,5 \\
\hline $81-86$ & 10 & 83,5 & 6972,25 & 835 & 69722,5 & 25 \\
\hline $87-92$ & 9 & 89,5 & 8010,25 & 805,5 & 72092,25 & 22,5 \\
\hline$\sum$ & 40 & 447 & 33931,5 & 3118 & 246604 & 100 \\
\hline
\end{tabular}

Nilai rata- rata post test diperoleh dengan membagi jumlah keseluruhan nilai siswa (fi.xi) 3118 dengan frekuensi jumlah siswa (fi) 40 sehingga diperoleh nilai rata-rata post test $(\overline{\mathrm{x}})$ 77,95 dan standart deviasi 9,55. Median (Me) diperoleh dengan mencari nilai tengah frekuensi kelas median pada fi yaitu 7 sehingga diperoleh nilai median 79,64 dan Modus (Mo) diperoleh dengan mencari frekuensi nilai yang paling sering muncul yaitu 10 sehingga nilai modus yaitu 85 . Berikut ini disajikan diagram data nilai post test siswa 
Siska Anggreni Lubis, Mega Dwi Pertiwi, Saiful B : Pengaruh Model Cooperative Integrated Reading and Composition Terhadap Hasil Belajar Siswa Pada Materi Ekosistem di SMA Nurul Amaliyah Tanjung Morawa

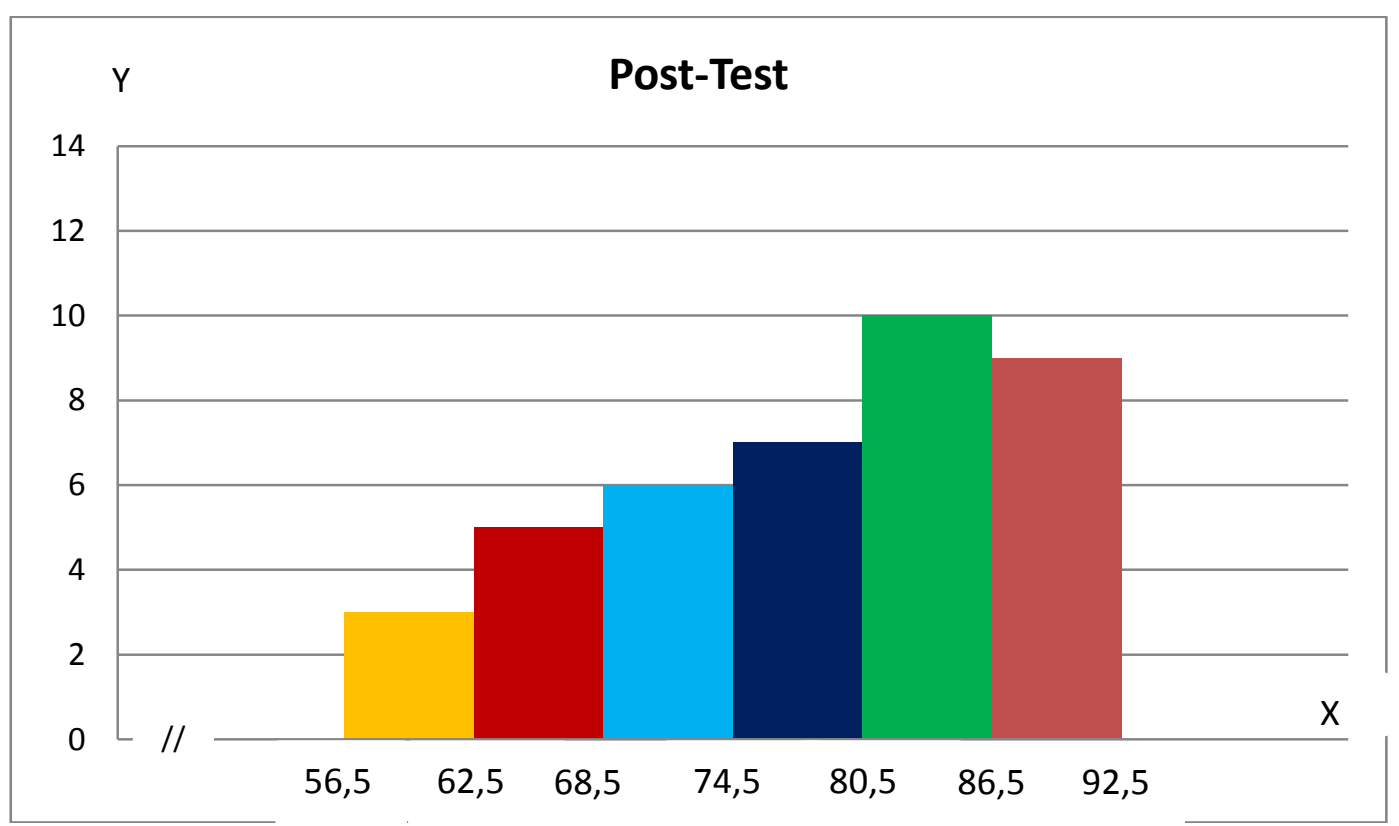

\section{Gambar . Diagram Nilai Post test Siswa}

\section{Uji Hipotesis}

Berdasarkan hasil perhitungan yang telah dilakukan rata- rata dari perbedaan pre test dengan post test adalah sebesar 15,45 dan jumlah kuadrat deviasi sebesar 2127,9 dengan menggunakan nilai tersebut maka dapat diketahui besar $t_{\text {hitung }}$ sebesar 13,21 . Nilai $t_{\text {hitung }}$ yang diperoleh selanjutnya dibandingkan dengan nilai $t_{\text {tabel }}$ diketahui bahwa $t_{\text {hitung }}>t_{\text {tabel }}$ atau 13,21 > 1,68 maka Ha diterima dan Ho ditolak, sehingga dinyatakan bahwa ada pengaruh yang signifikan penggunaan model Cooperative Integrated Reading and Composition terhadap hasil belajar siswa pada materi ekosistem.

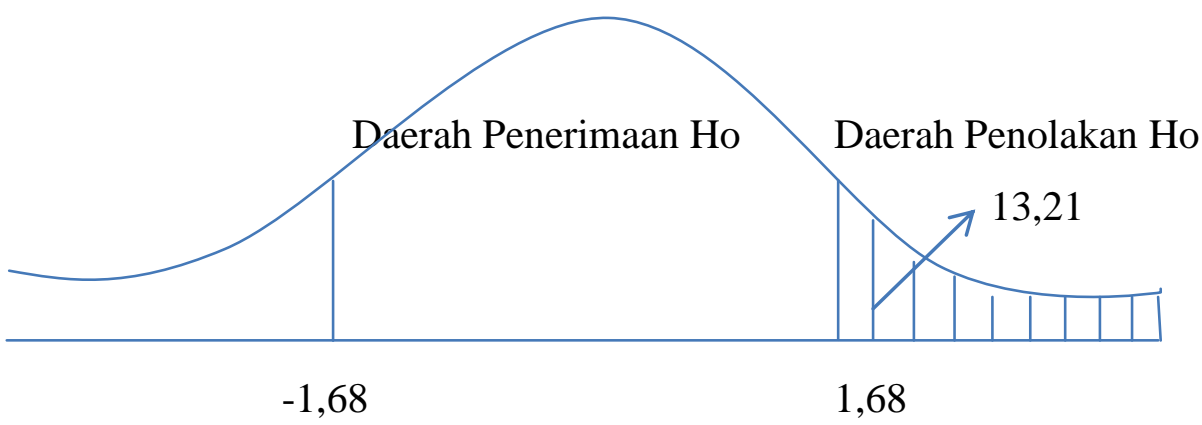

Gambar .Kurva Hipotesis

\section{KESIMPULAN}

Berdasarkan hasil penelitian yang telah dilakukan, maka dapat disimpulkan:

- Sebelum penggunaan model Cooperative Integrated Reading and Composition pada materi Ekosistem di SMA Nurul Amaliyah Tanjung morawa hasil belajar tidak mencapai Kriteria Ketuntasan Minimal 70 diperoleh persentase siswa yang tuntas sebanyak 9 orang $(22,5 \%)$ dan yang tidak tuntas 31 orang $(77,5 \%)$ dengan rata- rata 60,85 . 
Siska Anggreni Lubis, Mega Dwi Pertiwi, Saiful B : Pengaruh Model Cooperative Integrated Reading and Composition Terhadap Hasil Belajar Siswa Pada Materi Ekosistem di SMA Nurul Amaliyah Tanjung Morawa

- Hasil belajar Biologi di SMA Nurul Amaliyah Tanjung Morawa mengalami peningkatan dan mencapai Kriteria Ketuntasan Minimal (KKM) setelah penggunaan model Cooperative Integrated Reading and Composition pada materi Ekosistem dimana persentase siswa yang tuntas sebanyak 32 orang $(80 \%)$ dan yang tidak tuntas sebanyak 8 orang (20\%) dengan rata- rata 77,95 .

- Terdapat pengaruh yang signifikan penggunaan model Cooperative Integrated Reading and Composition terhadap hasil belajar siswa pada materi Ekosistem sesuai dengan hasil perhitungan $t_{\text {hitung }}>t_{\text {tabel }}$ yaitu 13,21 $>1,68$ maka Ha diterima dan Ho ditolak.

\section{SARAN}

Berdasarkan simpulan penelitian di atas, maka penulis memberikan beberapa saran sebagai berikut :

- Bagi guru dan calon guru khususnya bidang studi Biologi menggunakan model Cooperative Integrated Reading and Composition dapat dijadikan salah satu model pembelajaran di kelas untuk meningkatkan hasil belajar.

- Bagi peneliti lainnya yang ingin meneliti tentang pengaruh model pembelajaran Cooperative Integrated Reading and Composition sebaiknya model ini digunakan pada materi yang lain agar penerapannya lebih bervariasi

\section{DAFTAR PUSTAKA}

Al- Qur'an Al Karim Surah Al-Mujadilah 58 ayat 11

Arikunto, Suharsimi. 2006. Prosedur Penelitian. Jakarta: Bumi Aksara. .2012. Dasar-dasar Evaluasi Pendidikan Edisi 2. Jakarta: Bumi aksara.

Aryulina, Diah. 2007. Biologi 1 SMA dan MA untuk Kelas X. Jakarta: esis.

Awalani, Indikhiro. 2010. Penerapan Model Pembelajaran Cooperative Integrated Reading and Composition (CIRC) Berbasis Komputer untuk Meningkatkan Hasil Belajar Siswa Pada Pembelajaran TIK http://file.upi.edu/direktori/jurnal/pendidikan tik/ diakses pada tanggal 17 Maret 2014

Istarani. 2012. 58 Model Pembelajaran Inovatif. Medan: Media Persada.

Khairani, Makmun. 2013. Psikologi Belajar. Medan: Media Persada.

Muhammad, Rosyadi. 2010. Model Pembelajaran kooperatif Tipe CIRC http://matematikacerdas.wordpress.com/2010/01/28/modelpembelajaran kooperatif-tipe-circ/, diakses pada tanggal 13 Maret 2014

Munadi,Yudhi. 2013. Media Pembelajaran. Jakarta: GP Press Group.

Musfiqon. 2010. Belajar dan Pembelajaran. Jakarta: Prestasi Pustaka. 
Siska Anggreni Lubis, Mega Dwi Pertiwi, Saiful B : Pengaruh Model Cooperative Integrated Reading and Composition Terhadap Hasil Belajar Siswa Pada Materi Ekosistem di SMA Nurul Amaliyah Tanjung Morawa

Pratiwi, D, A.2007. Biologi untuk SMA Kelas X. Jakarta: Erlangga.

Sudjana. 2002. Metoda Statistika. Bandung: Tarsito.

Sugiyono, 2013. Metode Penelitian Pendidikan Kuantitatif, Kualitatif dan R\&D. Jakarta: Alfabeta.

Suprihatiningrum, Jamil. 2013. Strategi Pembelajaran. Jogjakarta: Ar- Ruzz Media.

Suprijono, Agus. 2010. Cooperative Learning Teori \& Aplikasi Paikem. Yogyakarta: Pustaka Pelajar.

Suyatno, Imam. 2009. Memahami Tindakan Pembelajaran. Bandung: PT. Retika Aditama.

Raharjo, Pranoto. 2012. Trik menulis Skripsi \& Menghadapi Presentasi. Jogjakarta: Platinum.

Ruhimat, Toto. 2011. Kurikulum dan Pembelajaran. Jakarta: Rajawali pers.

Trianto. 2009. Mendesain Model Pembelajaran Inovatif- Progresif. Jakarta: Kencana Prenada Media Group.

http://www.artikellingkunganhidup.com/pengertian-polusi-dan-limbah.html 